\title{
Bioactivity and Chemical Constituents of the Essential Oil from Dendranthema indicum (L.) Des Moul. against Two Stored Insects
}

\author{
Wen-Juan Zhang ${ }^{1}$, Chun-Xue You', Kai Yang ${ }^{1}$, Ying Wang ${ }^{1}$, Yang Su ${ }^{2}$, Zhu-Feng Geng ${ }^{3}$, \\ Shu-Shan $\mathrm{Du}^{1 *}$, Cheng-Fang Wang ${ }^{1,4 *}$, Zhi-Wei Deng $^{3}$ and Yong-Yan Wang ${ }^{1}$
${ }^{1}$ Beijing Key Laboratory of Traditional Chinese Medicine Protection and Utilization, Beijing Normal University (NO.19 Xinjiekouwai Street, Beijing 100875, CHINA)
${ }^{2}$ Tibet Judicial Police Hospital (NO.10 Zhaji Road, Chengguan District, Lhasa 850000, Tibet Autonomous Region, CHINA)
${ }^{3}$ Analytical and Testing Center, Beijing Normal University (NO.19 Xinjiekouwai Street, Beijing 100875, CHINA) for Disease Control and Prevention (Xicheng District, Beijing 100088, CHINA) \\ ${ }^{4}$ China CDC Key Laboratory of Radiological Protection and Nuclear Emergency, National Institute for Radiological Protection, Chinese Center
}

\begin{abstract}
Dendranthema indicum (L.) Des Moul. is a perennial herb commonly used as a traditional Chinese medicine for a long time. In this work, we took Dendranthema indicum as a target plant and two stored insects which include Tribolium castaneum and Stegobium paniceum adults as target insects. Essential oil obtained from Dendranthema indicum was analyzed by gas chromatography-mass spectrometry (GC-MS). A total of 31 components representing $92.44 \%$ of the oil were identified and the main compounds were found to be chamazulene (15.93\%), $\beta$-caryophyllene $(13.78 \%)$, germacrene $D(9.11 \%)$, and $b$-cis-farnesene $(6.59 \%)$. With a further isolation, three constituents were obtained from the essential oil and identified as chamazulene, $\beta$-caryophyllene and eucalyptol. Significantly, in the progress of assay, it showed that the essential oil and chamazulene exhibited stronger insecticidal and repellent activities against Stegobium paniceum than Tribolium castaneum. The results indicate that additional to its traditional use as Chinese medicinal herb, the essential oil of Dendranthema indicum aerial parts and isolated compounds have potential to be developed into natural insecticides or repellents for control of insects in stored grains.
\end{abstract}

Key words: D. indicum, T. castaneum, S. paniceum, contact toxicity, repellency, chemical composition

\section{INTRODUCTION}

The red flour beetle, Tribolium castaneum Herbst are the most widespread and destructive primary insect pests of stored cereals ${ }^{1)}$. Drugstore beetle, Stegobium paniceum, as an omnivorous stored insects, are widespread in the world. The infestations of stored product insects can not only cause significant losses due to the consumption of grains but also result in the rise of temperature and moisture which lead to an accelerated growth of molds, including toxigenic species ${ }^{2)}$. Synthetic insecticides and fumigants were widespread used in control of insects in stored grains and traditional chinese medicinal materials, that has led to problems such as disturbances of the environment, increasing costs of application, pest resurgence, pest resistance to pesticides, and lethal effects on non-target organisms in addition to direct toxicity to users $^{3)}$. These prob- lems have needed a search for alternative eco-friendly insect pest control methods ${ }^{4)}$. Since it has the advantage of providing novel modes of action against insects and reducing the risk of cross-resistance as well as offering new leads for design of target-specific molecules, botanical pesticide was expected to be developed into new natural pesticide ${ }^{5,6)}$. According to a report in the literature, the use of essential oils or their constituents with low mammalian toxicity can effectively prevent and/or suppress insect pest especially in storage ${ }^{5)}$. Moreover, essential oils from many plants including medicinal herbs, spices and fruits have been evaluated with success for insecticidal/repellency activity

Abbreviations: D. indicum: Dendranthema indicum; T. castaneum: Tribolium castaneum; S. paniceum: Stegobium paniceum; RI: Retention Index; MS: mass spectrum; DEET: N,N-diethyl-3-methyl-benzamide.

\footnotetext{
*Correspondence to: Shu-Shan Du, Beijing Key Laboratory of Traditional Chinese Medicine Protection and Utilization, Beijing Normal University, NO.19 Xinjiekouwei Street, Beijing 100875, CHINA

E-mail: dushushan@bnu.edu.cn

Accepted January 7, 2015 (received for review October 18, 2014)

Journal of Oleo Science ISSN 1345-8957 print / ISSN 1347-3352 online

http://www.jstage.jst.go.jp/browse/jos/ http://mc.manusriptcentral.com/jjocs
} 
against stored-product insects/mites, in some cases, have been proven more effective than traditionally used organophosphorus pesticides ${ }^{7-10)}$. In present study, insecticidal and repellent activities of $D$. indicum essential oil and its three main active ingredients against $T$. castaneum and $S$. paniceum were investigated.

\section{EXPERIMENTAL PROCEDURES}

\subsection{Chemicals}

Chamazulene, $\beta$-caryophyllene and eucalyptol were isolated from $D$. indicum essential oil on a silica gel column (45 mm $\times 500$ mm) (Qingdao Marine Chemical Plant, Shandong province, China).

\subsection{Material}

\subsubsection{Plants}

Dried aerial parts (10.0 kg of leaves, stems and flowers) of $D$. indicum were harvested in October 2013 from Jining City $\left(35.23^{\circ} \mathrm{N}\right.$ latitude and $116.33^{\circ} \mathrm{E}$ longitude), Shandong Province of China. The plant was identified by Dr. Liu, Q.R. (College of Life Sciences, Beijing Normal University, Beijing, China) and a voucher specimen (BNU-CMH-Dushushan-2013-10-04-011) was deposited at the Herbarium (BNU) of College of Resource Sciences, Beijing Normal University, China.

\subsubsection{Insects}

The red flour beetle, Tribolium castaneum and drugstore beetle, Stegobium paniceum adults (about $7 \pm 2$ days old) were collected from laboratory cultures maintained for the last 2 years in dark in incubators at $29 \pm 1{ }^{\circ} \mathrm{C}$ and $70-80 \%$ relative humidity. The insects were keeped in glass containers $(0.5 \mathrm{~L})$ containing wheat flour at $12-13 \%$ moisture content mixed with yeast (10:1, w/w). Adults used in all the experiments were about $7 \pm 2$ days old.

\subsection{Isolation of the Essential Oil and Purification of Four Constitunent Compounds}

The aerial parts were air-dried for one week and ground to a powder and then subjected to hydrodistillation using a modified Clevenger-type apparatus for $6 \mathrm{~h}$. Anhydrous sodium sulphate was used to remove water after extraction. The essential oil was stored in airtight containers in a refrigerator at $4^{\circ} \mathrm{C}$ for subsequent experiments. The crude essential oil ( $8 \mathrm{~mL}$ ) was chromatographed on a silica gel (Qingdao Marine Chemical Plant, Shandong province, China) column (40 mm i.d., $500 \mathrm{~mm}$ length) on three steps. First, chromatographed on by gradient elution with petroleum ether, then with petroleum ether-ethyl acetate, and last with ethyl acetate. Total fractions $(200 \mathrm{~mL})$ were collected and maintained at $35^{\circ} \mathrm{C}$, and similar fractions according to thin layer chromatography (TLC) profiles were combined to yield 40 fractions. Fractions (1-4, 22-29) were proned to possess contact toxicity and repellency, with similar TLC profiles, were pooled and further purified by preparative silica gel column chromatography (PTLC) until obtain the pure compounds which were determined as chamazulene (1, 0.82g), $\beta$-caryophyllene (2, 0.71g) and eucalyptol $(3,0.06 \mathrm{~g})$. The three isolated compounds were identified based on nuclear magnetic resonance. ${ }^{1} \mathrm{H}$ and ${ }^{13} \mathrm{C}$-NMR spectra were recorded on Bruker Avance DRX 500 instruments using $\mathrm{CDCl}_{3}$ as solvent with TMS as internal standard.

\subsection{GC-FID and GC-MS analysis}

GC-MS analysis was run on a Thermo Finnigan Trace DSQ instrument equipped with a flame ionization detector (FID) and a capillary column of HP-5MS (30 m × $0.25 \mathrm{~mm} \times$ $0.25 \mu \mathrm{m})$. The column temperature was programmed at $50^{\circ} \mathrm{C}$ for $2 \mathrm{~min}$, then increased at a speed of $2^{\circ} \mathrm{C} / \mathrm{min}$ to the temperature of $150^{\circ} \mathrm{C}$ and held for $2 \mathrm{~min}$, and then increased at $10^{\circ} \mathrm{C} / \mathrm{min}$ until the final temperature of $250^{\circ} \mathrm{C}$ was reached, where it was held for $5 \mathrm{~min}$. The temperature of injector was maintained at $250^{\circ} \mathrm{C}$ and the volume injected was $0.1 \mu \mathrm{L}$ of $1 \%$ solution (diluted in $n$-hexane). The carrier gas was helium at flow rate of $1.0 \mathrm{~mL} / \mathrm{min}$. Spectra were scanned from 50 to $550 \mathrm{~m} / z$. Most constituents were identified by comparing their retention indices with those reported in the literatures. Under the same operating conditions, the retention indices were determined in relation to a homologous series of $n$-alkanes $\left(\mathrm{C}_{5}-\mathrm{C}_{36}\right)$. Further identification of the isolated constitutes was made by comparing their mass spectra with those stored in NIST 05 and Wiley 275 libraries or with mass spectra from literature ${ }^{11)}$. Relative percentages of the individual components of the essential oil were obtained by averaging the GC peak area\% reports.

\subsection{Isolated Constituent Compounds}

Chamazulene (1, Fig. 1). Dark blue oil. ${ }^{1} \mathrm{H}-\mathrm{NMR}(500$ $\left.\mathrm{MHz}, \mathrm{CDCl}_{3}\right) \delta(\mathrm{ppm}): 8.19(1 \mathrm{H}, \mathrm{s}, \mathrm{H}-4), 7.65(1 \mathrm{H}, \mathrm{d}, J=3.6$ $\mathrm{Hz}, \mathrm{H}-2), 7.41$ (1H, d, $J=3.6 \mathrm{~Hz}, \mathrm{H}-1), 7.02(1 \mathrm{H}, \mathrm{d}, J=10.5$ Hz, H-6) , 7.00 (1H, d, $J=10.5$ Hz, H-7), 2.86 (3H, s, H-11), $2.69(2 \mathrm{H}, \mathrm{s}, \mathrm{H}-12)$, $2.68(3 \mathrm{H}, \mathrm{s}, \mathrm{H}-14), 1.37(3 \mathrm{H}, \mathrm{t}, J=7.5 \mathrm{~Hz}$, $\mathrm{H}-13) ;{ }^{13} \mathrm{C}-\mathrm{NMR}\left(125 \mathrm{MHz}, \mathrm{CDCl}_{3}\right) \delta(\mathrm{ppm}): 144.32(\mathrm{C}-8)$,

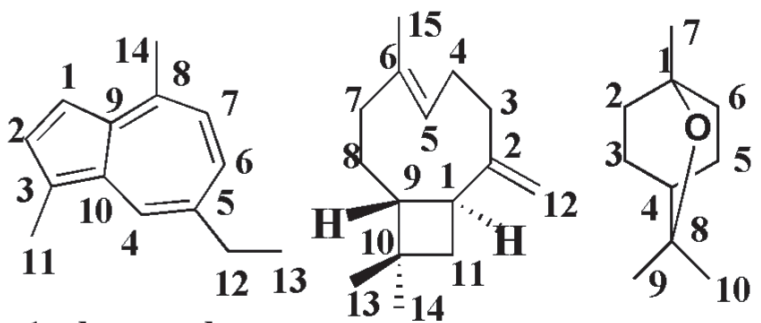

1. chamazulene 2. 3 -caryophyllene 3. eucalyptol

Fig. 1 Constituent compounds isolated from the essential oil of $D$. indicum aerial parts. 
$137.32(\mathrm{C}-9), 136.44(\mathrm{C}-10), 136.19(\mathrm{C}-2), 136.13(\mathrm{C}-6)$, $135.75(\mathrm{C}-5), 134.76(\mathrm{C}-4), 124.96(\mathrm{C}-7), 125.08(\mathrm{C}-3)$, 112.76 (C-1), 33.85 (C-12), 24.13 (C-14), 17.42 (C-13), $12.90(\mathrm{Me}(\mathrm{C}-3))$. Its NMR data were identical to the literature data ${ }^{12)}$.

B-Caryophyllene (2, Fig. 1). Colorless oil. ${ }^{1} \mathrm{H}-\mathrm{NMR}(500$ $\left.\mathrm{MHz}, \mathrm{CDCl}_{3}\right) \delta(\mathrm{ppm}): 5.33(1 \mathrm{H}, \mathrm{m}, \mathrm{H}-5), 4.97(1 \mathrm{H}, \mathrm{s}$, $\mathrm{H}-12 \mathrm{a}), 4.85(1 \mathrm{H}, \mathrm{s}, \mathrm{H}-12 \mathrm{~b}), 2.37(1 \mathrm{H}, \mathrm{m}, \mathrm{H}-9), 2.33(1 \mathrm{H}, \mathrm{m}$, H-7b), $2.23(1 \mathrm{H}, \mathrm{m}, \mathrm{H}-7 \mathrm{a}), 2.11(1 \mathrm{H}, \mathrm{m}, \mathrm{H}-1), 2.02(1 \mathrm{H}, \mathrm{m}$, H-6b), $1.94(1 \mathrm{H}, \mathrm{m}, \mathrm{H}-6 \mathrm{a}), 1.72(1 \mathrm{H}, \mathrm{m}, \mathrm{H}-2 \mathrm{~b}), 1.69(1 \mathrm{H}, \mathrm{m}$, $\mathrm{H}-3 \mathrm{~b}), 1.65-1.67(2 \mathrm{H}, \mathrm{m}, \mathrm{H}-10), 1.64(3 \mathrm{H}, \mathrm{s}, \mathrm{Me}-15), 1.60$ (1H, m, H-3a), 1.52 (1H, m, H-2a), 1.02 (3H, s, Me-12), 1.00 $(3 \mathrm{H}, \mathrm{s}, \mathrm{Me}-13) ;{ }^{13} \mathrm{C}-\mathrm{NMR}\left(125 \mathrm{MHz}, \mathrm{CDCl}_{3}\right) \delta(\mathrm{ppm}): 154.74$ (C-2), 135.58 (C-6), $124.31(\mathrm{C}-5), 111.67(\mathrm{C}-12), 53.54$ (C-9), 48.48(C-1), 40.33(C-11), 39.96 (C-7), 34.79 (C-3), 33.02 (C-10), 30.09 (C-13), 29.36 (C-8), 28.38 (C-4), 22.66 (C-14), $16.32(\mathrm{C}-15)$. The ${ }^{1} \mathrm{H}$ and ${ }^{13} \mathrm{C}-\mathrm{NMR}$ data were consistent with the literature data ${ }^{13)}$.

Eucalyptol (3, Fig. 1). Colorless oil. ${ }^{1} \mathrm{H}-\mathrm{NMR}(500 \mathrm{MHz}$, $\left.\mathrm{CDCl}_{3}\right) \delta(\mathrm{ppm}): 2.03(2 \mathrm{H}, \mathrm{t}, \mathrm{H}-2), 1.68(2 \mathrm{H}, \mathrm{t}, \mathrm{H}-6), 1.52$ $(4 \mathrm{H}, \mathrm{m}, \mathrm{H}-3,5), 1.42(1 \mathrm{H}, \mathrm{m}, \mathrm{H}-4), 1.25(6 \mathrm{H}, \mathrm{s}, \mathrm{H}-9,10)$, $1.07(3 \mathrm{H}, \mathrm{s}, \mathrm{H}-7) ;{ }^{13} \mathrm{C}-\mathrm{NMR}\left(125 \mathrm{MHz}, \mathrm{CDCl}_{3}\right) \delta$ (ppm): 73.61 (C-8), $69.77(\mathrm{C}-1), 32.94(\mathrm{C}-4), 31.51$ (C-3, 5), 28.89 (C-2, 6), 27.58(C-7), $22.83(\mathrm{C}-9,10)$. The ${ }^{1} \mathrm{H}$ and ${ }^{13} \mathrm{C}-\mathrm{NMR}$ data were in agreement with the reported data ${ }^{14)}$.

\subsection{Bioactivity}

\subsubsection{Contact activity}

The contact toxicity of the essential oil and the three isolated compounds against T. castaneum and S. paniceum adults was measured as described by Liu and $\mathrm{Ho}^{1)}$. The contact toxicity of the essential oil and the three isolated compounds against $S$. paniceum followed the same way. A lot of range-finding studies were conducted to determine the appropriate testing concentrations. Finally, the essential oil and three isolated compounds with five concentrations were prepared in $n$-hexane. Aliquots of $0.5 \mu \mathrm{L}$ of the dilutions were topically applied to the dorsal thorax of the insects. Controls were determined with $n$-hexane. Ten insects were used for each concentration and control, and the experiment was replicated five times. Then, both treated and control insects were transferred to glass vials with culture media and kept in incubators. Mortality of tested insects was recorded after $24 \mathrm{~h}$ and the observed mortality data were corrected for control mortality using Abbott's formula. The Probit analysis (IBM SPSS V20.0) ${ }^{15,10)}$ was used to abtain $\mathrm{LD}_{50}$ values. The positive control, pyrethrins (pyrethrin I, 24\%; pyrethrin II, 13\%; cinnerin I, $2 \%$; cinnerin II, 2\%; jasmolin I, 1\%; jasmolin II, 1\%) was purchased from Dr. Ehrenstorfer, Germany.

2.6.2 Repellency tests

The repellent activity of the essential oil and three isolated compounds against $T$. castaneum and S. paniceum adults was tested using previous method ${ }^{16)}$. Petri dishes $(9$ $\mathrm{cm}$ in diameter)were used to confine test insects during the experiment. Crude essential oil and its three isolated compounds were diluted to five concentrations (39.32, $7.86,1.57,0.31$ and $\left.0.06 \mathrm{~nL} / \mathrm{cm}^{2}\right)$ with $n$-hexane, and $n$ hexane was used as the control. Filter paper $(9 \mathrm{~cm}$ in diameter) was cut in half and each concentration with $500 \mu \mathrm{L}$ was separately applied to half of the filter paper with a micropipette at the same time. $500 \mu \mathrm{L}$ of $n$-hexane was used in control on the other half. The treated and control half filter paper were air-dried for $30 \mathrm{~s}$ to remove the solvent, re-attached with adhesive tape, and kept in $9 \mathrm{~cm}$ glass Petri dishes. Twenty insects of both sexes were released at the center of each filter paper disk, and a cover was placed over the Petri dish. Five replicates were used, and the experiment was repeated three times. Counts of insects present on each strip were made at 2 and $4 \mathrm{~h}$ after exposure. The percent repellency $(\mathrm{PR})$ of the volatile oil and its isolated compounds was then calculated using the formula:

$$
P R(\%)=[(\mathrm{Nc}-\mathrm{Nt}) /(\mathrm{Nc}+\mathrm{Nt})] \times 100
$$

Where Nc is the number of insects present in the negative control half and Nt is the number of insects present in the treated half. Analysis of variance (One-Way ANOVA and GLM Univariate) and Tukey's test were conducted by using SPSS 20.0 for Windows 2007. Percentage of mortality data were subjected to an arcsine square-root transformation before variance and Tukey's tests. A commercial repellent, $\operatorname{DEET}(N, N$-diethyl-3- methylbenzamide), was purchased from the National Center of Pesticide Standards (8 Shenliao West Road, Tiexi District, Shenyang 110021, China) and used as a positive control.

\section{RESULTS and DISCUSSION}

\subsection{Chemical compounds of the essential oil}

The $D$. indicum essential oil was yellow with a yield of $0.08 \%(\mathrm{v} / \mathrm{w})$ and density of $0.91 \mathrm{~g} / \mathrm{mL}$. GC-MS and GC-FID analysis of $D$. indicum essential oil revealed 31 components representing $92.44 \%$ of the oil (Table 1) and the main compounds of the essential oil were chamazulene $(15.93 \%), \beta$-caryophyllene $(13.78 \%)$, germacrene D $(9.11 \%)$ and $b$-cis-farnesene $(6.59 \%)$.

The chemical composition of the essential oil of $D$. indicum aerial parts in the present study was not the same as that reported in previous studies. For example, compounds in higher amounts present in essential oil of $D$. indicum in Hubei, Guangdong and Guangxi province of China were camphor $(31.38 \%)$, borneol $(41.21 \%)$ and isobornyl acetate $(46.00 \%)$, respectively ${ }^{17}$. What's more, the content and composition of the volatile oil of $D$. indicum were various with different extraction methods. In the literature, the essential oil from the dried flowers of $D$. indicum was obtained by supercritical fluid extration 
W. J. Zhang, C. X. You and K. Yang et al.

Table 1 Chemical composition of the essential oil of $D$. indicum aerial parts.

\begin{tabular}{|c|c|c|c|c|}
\hline Peak No. & Compound & $\mathrm{RI}^{\mathrm{a}}$ & Relative area $^{\mathrm{b}}(\%)$ & Identification Methods ${ }^{\mathrm{c}}$ \\
\hline 1 & $p$-Xylene & 800 & 2.60 & MS, RI \\
\hline 2 & $o$-Xylene & 811 & 2.79 & MS, RI \\
\hline 3 & 3-Carene & 1003 & 1.35 & MS, RI \\
\hline 4 & $D$-Limonene & 1027 & 2.56 & MS, RI \\
\hline 5 & Eucalyptol & 1031 & 3.78 & MS, RI, Co \\
\hline 6 & 2-Isopropyltoluene & 1104 & 0.36 & MS, RI \\
\hline 7 & Camphor & 1143 & 2.46 & MS, RI, Co \\
\hline 8 & $\alpha$-Caryophyllene & 1156 & 2.25 & MS, RI \\
\hline 9 & Terpinen-4-ol & 1176 & 1.04 & MS, RI \\
\hline 10 & $\alpha$-Terpineol & 1188 & 1.02 & MS, RI \\
\hline 11 & Isobornyl acetate & 1287 & 0.59 & MS, RI \\
\hline 12 & Terpinyl acetate & 1296 & 0.69 & MS, RI \\
\hline 13 & Senecioic acid & 1310 & 0.35 & MS, RI \\
\hline 14 & $\gamma$-Elemene & 1340 & 1.02 & MS, RI \\
\hline 15 & $b$-Elemene & 1389 & 2.63 & MS, RI \\
\hline 16 & $\beta$-Caryophyllene & 1426 & 13.78 & MS, RI \\
\hline 17 & $(\mathrm{Z}, \mathrm{Z})$ - $\alpha$-Farnesene & 1438 & 1.34 & MS, RI \\
\hline 18 & $\alpha$-Farnesene & 1440 & 2.44 & MS, RI \\
\hline 19 & Germacrene D & 1457 & 9.11 & MS, RI \\
\hline 20 & b-cis-Farnesene & 1458 & 6.59 & MS, RI \\
\hline 21 & $\alpha$-Calacorene & 1543 & 2.42 & MS, RI \\
\hline 22 & $\alpha$-Elemol & 1547 & 1.55 & MS, RI \\
\hline 23 & $\beta$-Eudesmol & 1632 & 0.92 & MS, RI \\
\hline 24 & Chamazulene & 1644 & 15.93 & MS, RI \\
\hline 25 & $(-)-b$-Cadinene & 1650 & 0.70 & MS, RI \\
\hline 26 & $\alpha$-Bisabolol & 1681 & 1.77 & MS, RI \\
\hline 27 & $\alpha$-Patchoulene & 1735 & 1.70 & MS, RI \\
\hline 28 & 3,3-Dimethylhexane & 1742 & 1.19 & MS, RI \\
\hline 29 & 4,4'-Dimethylbiphenyl & 1756 & 2.77 & MS, RI \\
\hline 30 & $\gamma$-Patchoulene & 1879 & 2.33 & MS, RI \\
\hline \multirow[t]{2}{*}{31} & Diisooctyl phthalate & 2135 & 2.51 & MS, RI \\
\hline & Total & & 92.44 & \\
\hline
\end{tabular}

${ }^{a}$ Retention index (RI) relative to the homologous series of $n$-hydrocarbons on the HP-5 MS capillary column.

${ }^{\mathrm{b}}$ Relative area (peak area relative to the total peak area).

${ }^{\mathrm{c}} \mathrm{MS}=$ mass spectrum, $\mathrm{Co}=$ co-injection with standard compound.

(SFE) and steam distillation (SD), and the highest contents were tetracosane $(7.50 \%)$ and bisabolol oxide $(11.87 \%)^{18)}$. Besides, different collection parts also led to different content and composition. The compositions of the essential oil from the leaves of $D$. indicum are more complex and diverse than that isolated from the flowers of $D$. indicum ${ }^{19)}$. These differences of chemical content and composition of the essential oils might be attributed to different harvest time and local, climatic and seasonal factors, storage duration of medicinal herbs as well as extraction method, and these differences may result in different biological activities $^{20)}$. 


\subsection{Bioactivity}

3.2.1 Insecticidial activity

3.2.1.1 Contact toxicity

In Table 2, though the essential oil of $D$. indicum aerial parts exhibited no contact toxicity against T. castaneum adults, it showed strong contact toxicity against $S$. paniceum adults with $\mathrm{LD}_{50}$ value of $5.82 \mu \mathrm{g} /$ adult. Compared with the positive control, pyrethrins $\left(\mathrm{LD}_{50}=1.22 \mu \mathrm{g} / \mathrm{adult}\right)$, the essential oil presented 5 times less toxicity against $S$. paniceum adults. What's more, chamazulene exhibited stronger contact toxicity against $S$. paniceum adults than T. castaneum adults with the $\mathrm{LD}_{50}$ values of 4.30 and 29.52 $\mu \mathrm{g} / \mathrm{adult}$, respectively. Actually, chamazulene only showed 4 times less contact toxicity than the positive control, pyrethrins. Moreover, as one of the main active compounds, chamazulene was proven to possess anti-inflammatory activity in vivo, by inhibiting the leukotriene synthesis, and to inhibit lipid peroxidation ${ }^{21,22)}$. Chamazulene is a very promising compound and will be paid more attention in the future. While, $\beta$-caryophyllene exhibited least contact toxicity against both $T$. castaneum and $S$. paniceum adults with $\mathrm{LD}_{50}$ value of 46.77 and $30.08 \mu \mathrm{g} / \mathrm{adult}$, respectively. Eucalyptol showed better contact toxicity against $T$. castaneum $\left(\mathrm{LD}_{50}=18.83 \mu \mathrm{g} / \mathrm{adult}\right)$ than $S$. paniceum $\left(\mathrm{LD}_{50}=\right.$ $20.77 \mu \mathrm{g} / \mathrm{adult}$ ), but less toxicity compared with the positive control, pyrethrins. What's more, both $\beta$-caryophyllene and eucalyptol were proven to possess insecticidal activity against Lasioderma serricorne ${ }^{23)}$ and Sitophilus zeamais $^{24)}$. However, considering the currently used insecticides are synthetic insecticides and promising contact activity of $D$. indicum essential oil and its isolated compounds, they have exhibited potential to be developed into possible natural insecticides for the stored product insects. 3.2.2 Repellent activity

In Fig. 2, the essential oil of $D$. indicum and its isolated constituents exhibites potential repellent activity against $T$. castaneum and $S$. paniceum adults, expecially towards $T$. castaneum adults. The results presented in Fig. 2 showed that the essential oil and chamazulene possess much stronger repellent activity against $T$. castaneum adults at both $2 \mathrm{~h}$ and $4 \mathrm{~h}$ after exposure at five tested concentrations. However, $\beta$-caryophyllene and eucalyptol exhibited much weaker repellent activity campared with the positive control, DEET. Hence, the strong repellency against $T$. castaneum adults might be attributed to the synergistic effects of its diverse major and minor components.

When it comes to $S$. paniceum adults, the essential oil and its isolated compounds showed weaker repellent activity than that against T. castaneum adults. In Fig. 3, $\beta$-caryophyllene showed the weakest repellent activity against $S$. paniceum adults at all tested concentrations at both $2 \mathrm{~h}$ and $4 \mathrm{~h}$ after exposure. At tested concentration of $0.31 \mathrm{~nL} / \mathrm{cm}^{2}$, eucalyptol exhibited the strongest repellency against $S$. paniceum adults at both $2 \mathrm{~h}$ and $4 \mathrm{~h}$ after exposure. What's more, at the concentration of $39.32 \mathrm{~nL} / \mathrm{cm}^{2}$, the essential oil and chamazulene showed the same repellency against $S$. paniceum adults at $2 \mathrm{~h}$ after exposure, and stronger repellent activity at $4 \mathrm{~h}$ after exposure when campared with DEET.

The above results indicates that the difference insecticidal and repellent activity between $T$. castaneum and $S$. paniceum adults might be attributed to the different mechanism. However, further research should be conducted in the future.

\section{CONCLUSION}

Based on mass screening, the essential oil of D. indicum and its three isolated constituents were examined for in-

Table 2 Contact toxicity of the essential oil of $D$. indicum aerial parts and its constituents against T. castaneum and S. paniceum adults.

\begin{tabular}{clcccc}
\hline Insects & \multicolumn{1}{c}{ Treatment } & $\mathrm{LD}_{50} *(\mu \mathrm{g} /$ adult $)$ & \multicolumn{1}{c}{$95 \% \mathrm{FL} * *$} & Slope $\pm \mathrm{SE}$ & Chi square $\left(\chi^{2}\right)$ \\
\hline \multirow{5}{*}{ Tribolium } & D. indicum & - & - & - & - \\
castaneum & Chamazulene & 29.52 & $27.91-31.04$ & $6.38 \pm 0.80$ & 6.129 \\
& $\beta$-Caryophyllene & 46.77 & $41.99-52.36$ & $3.02 \pm 0.37$ & 17.26 \\
& Eucalyptol & 18.83 & $17.13-20.69$ & $4.86 \pm 0.50$ & 16.56 \\
& Pyrethrins *** & 0.26 & $0.22-0.30$ & $3.34 \pm 0.32$ & 13.11 \\
& $D$. indicum & 5.82 & $4.97-6.59$ & $2.77 \pm 0.39$ & 9.81 \\
& Chamazulene & 4.30 & $3.63-4.93$ & $2.23 \pm 0.32$ & 13.43 \\
Stegobium & $\beta$-Caryophyllene & 30.08 & $24.01-33.72$ & $3.93 \pm 0.79$ & 7.83 \\
paniceum & Eucalyptol & 20.77 & $18.59-23.17$ & $3.03 \pm 0.36$ & 10.26 \\
& Pyrethrins *** & 1.22 & $0.67-1.80$ & $0.69 \pm 0.15$ & 6.21 \\
\hline
\end{tabular}

$* 50 \%$ of lethal dose, $* *$ fiducial limits, $* * *$ data from Yang ${ }^{10)}$. 


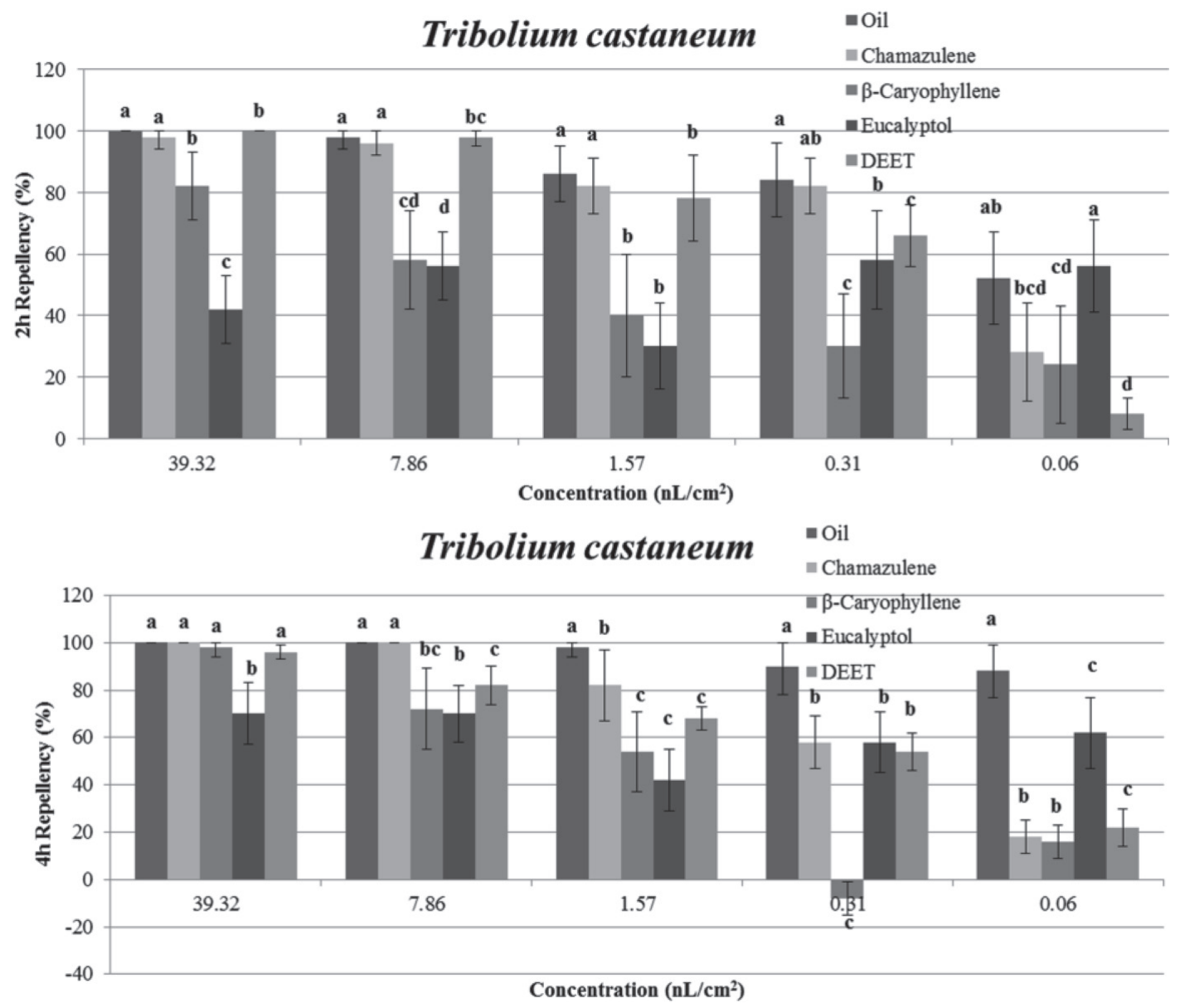

Fig. 2 Percentage repellency (PR) of the essential oil from $D$. indicum aerial parts and its isolated constituents against T. castaneum at $2 \mathrm{~h}$ and $4 \mathrm{~h}$ after exposure $\mathrm{a}^{\mathrm{a}}$.

${ }^{a}$ means in the same column followed by the same letters do not differ significantly $(p>0.05)$ in ANOVA and Tukey's tests. PR was subjected to an arcsine square-root transformation before ANOVA and Tukey's tests.

secticidal and repellent activity against T. castaneum and $S$. paniceum adults. The essential oil and chamazulene possessed strong contact toxicity against $S$. paniceum adults, although they were 5 and 4 times less toxic to the $S$. paniceum adults compared to commercial insecticide Pyrethrins. The essential oil and chamazulene also exhibited strong repellent activity against $T$. castaneum adults campared with the positive control, DEET. These findings, considered together, suggest that the essential oil and its isolated constituents show potential for the development as natural insecticides or repellents for stored products.

\section{ACKNOWLEDGMENT}

This project was supported by the National Natural Science Foundation of China (No. 81374069), Beijing Municipal Natural Science Foundation (No. 7142093) and Fundamental Research Funds for the Central Universities.

\section{REFERENCES}

1) Liu, Z. L.; Ho, S. H. Bioactivity of the essential oil extracted from Evodia rutaecarpa Hook f. et Thomas against the grain storage insects, Sitophilus zeamais Motsch and Tribolium castaneum(Herbst). J. Stored Prod. Res. 35, 317-328(1999).

2) Magan, N.; Hope, R.; Cairns, V.; Aldred, D. Postharvest fungal ecology: impact of fungal growth and mycotoxin accumulation in stored grain. Eur. J. Plant Pathol. 109, 723-730 (2003).

3) Isman, M. B. Plant essential oils as green pesticides for pest and disease management. ACS Sym. Ser. 887, 41-51 (2004).

4) Phillips, T. W.; Throne, J. E. Biorational approaches to managing stored-product insects. Annu. Rev. Entomol. 55, 375 (2010).

5) Isman, M. B. Botanical insecticides, deterrents, and repellents in modern agriculture and an increasingly regulated world. Annu. Rev. Entomol. 51, 45-66 (2006). 

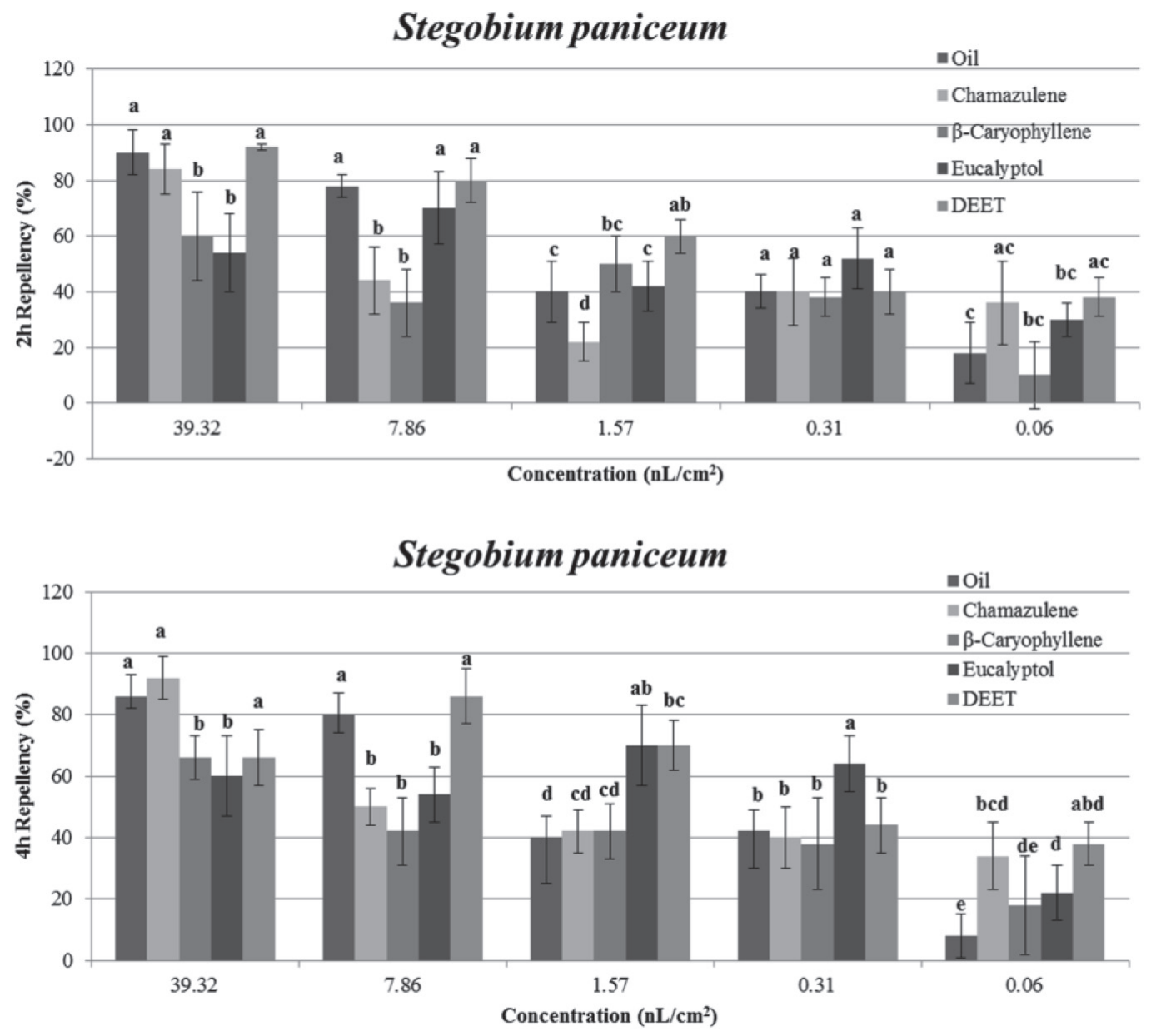

Fig. 3 Percentage repellency (PR) of the essential oil from D. indicum aerial parts and its isolated constituents against S. paniceum at $2 \mathrm{~h}$ and $4 \mathrm{~h}$ after exposure ${ }^{\mathrm{a}}$.

${ }^{a}$ means in the same column followed by the same letters do not differ significantly $(p>0.05)$ in ANOVA and Tukey's tests. PR was subjected to an arcsine square-root transformation before ANOVA and Tukey's tests.

6) Isman, M. B. Perspective botanical insecticides: for richer, for poorer. Pest Manag. Sci. 64, 8-11 (2008).

7) Chu, S. S.; Liu, Q. R.; Liu, Z. L. Insecticidal activity and chemical composition of the essential oil of Artemisia vestita from China. Biochem. Syst. Ecol. 38, 489-492 (2010).

8) Fang, R.; Jiang, C. H.; Wang, X. Y.; Zhang, H. M.; Liu, Z. L.; Zhou, L. G.; Du, S. S.; Deng, Z. W. Insecticidal activity of essential oil of Carum carvi fruits from China and its main components against two grain storage insects. Molecules 15, 9391-9402(2010).

9) Rajendran, S.; Srianjini, V. Plant products as fumigants for stored-product insects control. J. Stored Prod. Res. 44, 126-135(2008).

10) Yang, K.; Wang, C. F.; You, C. X.; Geng, Z. F.; Sun, R. Q.; Guo, S. S.; Du, S. S.; Liu, Z. L.; Deng, Z. W. Bioactivity of essential oil Litsea cubeba from China and its main compounds against two stored product insects. $J$. Asia-Pac. Entomol. 17, 459-466(2014).
11) Adams, R. P. Identification of essential oil components by gas chromatography/quadrupole mass spectroscopy. Allured: Carol Stream, IL, USA (2001).

12) Adam, K.-P.; Zapp, J. Biosynthesis of the isoprene units of chamomile sesquiterpenes. Phytochemistry 48, 953-959 (1998).

13) Ragasa, C. Y.; Espineli, D. L.; Agoo, E.; Del Fierro, R. S. Chemical constituents of Cinnamomum cebuense. Chin. J. Nat. Med. 11, 264-268(2013).

14) Ashnagar, A.; Naseri N. G.; Bayemani, A. Isolation and determination of the major chemical compounds present in essential oil of the leaves of Myrtus plant grown in Khuzestan Province of Iran. Asian J. Chem. 21, 4969-4975 (2009).

15) Sakuma, M. Probit analysis of preference data. Appl. Entomo. Zool. 33, 339-348(1998).

16) Zhang, J. S.; Zhao, N. N.; Liu, Q. Z.; Liu, Z. L.; Du, S. S.; Zhou, L.; Deng, Z. W. Repellent constituents of essential oil of Cymbopogon distans aerial parts against 
two stored-product insects. J. Agr. Food Chem. 59, 9910-9915(2011).

17） Zhang, Y. M.; Huang, Y. F.; Tao, L.; Huang, J. W. Chemical components of essential oils from Flos Chryanthemi Indici in different areas. China J. Chinese Medica 27, 265-267 (2002).

18) Zhou, X.; Mo, B. B.; Zhao, C.; Yang, X. S. Studies on the chemical constituents of the volatile oil from the flowers of Chrysanthemum indicum by supercritical fluid extraction. Chin. Pharm. J. 37, 170-172 (2002).

19) Liu, X. D.; Liu, C. F.; Lai, P. H.; Zhao, Y. K.; Liu, M.; Chen, K. Chemical components of the volatile oil of the stem and leaf from Chysanthemum indicum and its resistant to plant pathogenic fungi. Sci. Technol. Food Ind. 24, 98-104(2013).

20） Huang, B. K.; Lei, Y. L.; Tang, Y. H.; Zhang, J. C.; Qin, L. P.; Liu, J. Comparison of HS-SPME with hydrodistillation and SFE for the analysis of the volatile compounds of Zisu and Baisu, two varietal species of $P e$ - rilla frutescens of Chinese origin. Food Chem. 125, 268-275 (2011).

21) Safayhi, H.; Sabieraj, J.; Sailer, E. R.; Ammon, H. P.T . Chamazulene: an antioxidant-type inhibitor of leukotriene B4 formation. Planta Med. 60, 410-413 (1994).

22) Rekka, E. A.; Kourounakis, P.; Kourounakis, P. N. Investigation of the effect of chamazulene on lipid peroxidation and free radical processes. Res. Commun. Mol. Path. 92, 361-364(1996).

23) Zhang, W. J.; You, C. X.; Yang, K.; Chen, R.; Wang, Y.; Wu, Y.; Geng, Z. F.; Chen, H. P.; Jiang, H. Y.; Su, Y.; Lei, N.; Ma, P.; Du, S. S.; Deng, Z. W. Bioactivity of the essential oil of Artemisia argyi Lévl. et Van. and its main compounds against Lasioderma serricorne. $J$. Oleo Sci. 63, 829-837 (2014).

24) Chu, S. S.; Liu, S. L.; Liu, Q. Z.; Jiang, G. H.; Liu, Z. L. Chemical composition and insecticidal activities of the essential oil of the flowering aerial parts of Aster ageratoides. J. Serb. Chem. Soc. 78, 209-216 (2013). 